\title{
LA POLÉMICA CONSTRUCCIÓN DEL EDIFICIO DEL BANCO DE ESPAÑA EN SANTIAGO: PERIPECIAS DE POSTGUERRA
}

\author{
por \\ JUAN MANUEL CORRAL VARELA
}

\begin{abstract}
Cuando se ojea con detenimiento la prensa que la ciudad de Santiago leía en los primeros momentos de la postguerra, aquellos en los que no hacían más que remansarse los rencores generados por una contienda sufrida desde retaguardia, es fácil para cualquiera imaginar el incierto panorama que se ofrecía a la mirada de quien podía aún alzarla. Muchas novedades habían sacudido repentinamente a todo un orden, a toda una ciudad, llegando incluso algunas de ellas a conmover el espíritu de quienes, habiendo podido tomar posiciones seguras, libres de sospecha, en los dominios del nuevo régimen, seguían preocupándose por la integridad de la imagen que esa ciudad tenía. De este modo, la novedad que generó mayor polémica en todo este gris mundillo - al menos la que mayor difusión pública llegó a alcanzar - la constituyó, curiosamente, un edificio: capaz de despertar las conciencias estéticas de un amplio colectivo ciudadano, capaz de llevar a las hojas de los periódicos inquietudes de raíz arquitectónica, capaz de conseguir que en 1940, sólo un año después del fin de la guerra, a alguien, en el Ayuntamiento de Santiago, se le subieran los colores con la lectura de un mensaje enviado desde un despacho ministerial. Y no era precisamente una admiradora quien escribía:
\end{abstract}

«Iltrm. Sr.: Abandonada la ciudad de Santiago a sus iniciativas puede considerarse como milagroso el que a través de las vicisitudes que ha sufrido, se conserven sus monumentos, los edificios más caracterís-

"CUADERnOS DE ESTUdiOS GALLEGOS", Tomo XLII, Fascículo 107, Santiago 1995. 
ticos y muchos de sus conjuntos en condiciones que la hacen merecedora del título recientemente concedido de Monumento Nacional Histórico Artístico. Tal declaración obliga al estado a velar por la conservación de su carácter, acudiendo a remediar los desmanes que puedan cometerse en la erección de edificios que desvirtúan su condición eminentemente artística; desmanes casi siempre motivados por intereses particulares que echan en olvido el interés supremo de la Nación. Tal sucede con el inmueble que para el Banco de España se está construyendo en la Plaza de Platerías, uno de los lugares más bellos de la ciudad de Santiago de Compostela y cuya edificación es preciso atajar antes de que el daño sea irremediable».

Con fecha del 7 de septiembre de 1940 y con este tono, cargado con una dosis concentrada de humillante menosprecio, se dirigía al entonces Alcalde de Santiago, Marqués de Figueroa, nada más y nada menos que quien fue Ministro de Educación Nacional desde 1939 a 1951: el Señor Ibáñez Martín'. La reprimenda, transmitida a través de una carta firmada por el Director General de Bellas Artes, ponía fin a una sucesión de irregularidades que llevaban camino de injertar en plena plaza de Platerías un descomunal edificio de tres plantas - cuatro metros y medio superior al actualmente existente-, con su portada abierta a la Rúa do Vilar en un amplio chaflán y con un envoltorio formal evidentemente discordante con el espacio al que estaba destinado.

El edificio actual, fruto de continuas modificaciones y encaminado finalmente tras algunos drásticos pasos atrás, tampoco se hace merecedor de grandes elogios ${ }^{2}$. En realidad es resultado de la sucesión de impedimentos

\footnotetext{
${ }^{1}$ En la carta en que aparece recogido, guardada en el Archivo Municipal compostelano - como la mayor parte de los documentos manejados para la realización de este estudio - (carpeta Documentación Banco de España 1939-1949), no se nombra en ningún momento al señor Ibáñez Martín, sino que simplemente se habla en nombre del «Excm. Sr. Ministro»; sin embargo, el membrete del papel en que está escrita, indica que procede del Ministerio de Educación Nacional.

${ }^{2}$ José Luis Cabo Villaverde, haciéndose eco de la opinión de Díaz Pardo, se refiere a el como «... el horrible pastiche neocompostelano que sufrimos hoy.» (La Voz de Galicia: «Contrastres». 22-II-87). Y el propio Diaz Pardo, llevando al extremo sus iniciales apreciaciones sentenciaba: «Mas que el pastiche en si la barbaridad está en el gigantismo quc aplasta la escala de proporciones de los otros edificios de la plaza, incluida la Catedral... La dinámica, en una voladura controlada, no tendría una justificación mejor». (Isaac Diaz Pardo. Galicia hoy y el resto del mundo. Ed. do Couto, 1987, pp. 48-49).
} 
que a su crecimiento fueron poniendo, por un lado, una parte de la población compostelana; por otro, Don José María Banet - el arquitecto municipal que vivió desde ese cargo todo el período durante el que se adquirieron los terrenos y se construyó el edificio--; y, por último, la Academia de Bellas Artes de San Fernando. Todos ellos, con el respaldo de otras instituciones, evitaron que lo que hoy es sólo uno más de los mediocres ejemplos de arquitectura de postguerra ${ }^{3}$, merecedor de plausible indiferencia, se convirtiera además en un terrible y monumental adefesio inserto en el corazón mismo del patrimonio arquitectónico de Compostela.

El largo proceso que precedió a esta carta y a lo que ella supuso como inicio de definitiva «reparación», fue el siguiente:

Arranca la historia de la lógica aspiración que tenía el Banco de España de contar con un edificio propio en la ciudad de Santiago. La política de la entidad en este sentido había sido la misma desde finales del siglo pasado en todo el territorio nacional: allí donde el Banco contaba únicamente con un local arrendado (en la Plaza de la Universidad en este caso) intentaba hacerse con un solar bien situado - a ser posible en el centro histórico y económico de la ciudad - para poder levantar en él un edificio de nueva planta ${ }^{4}$.

Para ello, en el caso compostelano, según consta en la documentación existente, el Ayuntamiento ofertó al Banco otras posibilidades antes de que se decidiera a comprar las casas de Platerías.

Con fecha del 28 de mayo de 1934, en lo que supone la primera intervención de José María Banet, el ya entonces arquitecto municipal realiza un informe proponiendo al Ayuntamiento que facilite en lo necesario la opción de un solar existente en la zona del ensanche, entre la calle de la Senra, la Avenida de la Libertad y la Avenida de Figueroa, un lugar desde

\footnotetext{
${ }^{3}$ Habría que aclarar aquí que esta obra, como en muchos otros casos, no puede estrictamente incluirse en un marco estilístico-ideológico que lleve por título este de arquitectura de postguerra, aunque sí es factible si el marco funciona desde el punto de vista estrictamente cronológico.

${ }^{4}$ Saladina Iglesias, Lena: «Aportación al estudio de los edificios del Banco de España». Actas del V Congreso Español de Historia del Arte (II). Barcelona, 1984. pp. 185190. El propio arquitecto de la sucursal compostelana, Romualdo de Madariaga, confirmaba en la memoria del proyecto esa tendencia:

«El Banco, como siempre procura en este caso el mejor emplazamiento posible para su sucursal como corresponde a su importante misión y así lo tiene logrado en el centro de la ciudad, inmediata la Catedral, que agrupa muy cerca los centros oficiales y administrativo de ella; allí en la antigüedad existían "los caballeros cambeadores de moneda", cuya Hermandad, estableció D. Alfonso II en el siglo IX en beneficio de los peregrinos.».
}

"CUADERNOS DE ESTUDIOS GALLEGOS", Tomo XLII, Fascículo 107, Santiago 1995. 
donde arrancaría además la futura Rúa de Galicia, proyectada por Antonio Palacios. Trataba el arquitecto, en este documento, de ensalzar las posibilidades y buena situación que presentaba este solar frente a una hipotética ubicación del edificio en el casco histórico. Sin embargo, a los directivos del Banco esta última posibilidad les parecía desde un principio más sugestiva y, después de varios tanteos infructuosos, terminarían de concretarla en octubre de 1936, cuando obtuvieron del ayuntamiento presidido por Juan Varela de Limia, el primero formado tras el triunfo del alzamiento militar, autorización para comprar las casas situadas en la Plaza de Platerías, propiedad de Antonio Facal Varela, Alfredo Espinosa Orrea y Juan Carreira Pintos.

Los documentos que hemos podido consultar hacen recaer pues el «mérito» del arranque definitivo del proyecto sobre las espaldas de los representantes del nuevo régimen, aunque hemos de señalar también que durante la República estaban ya iniciadas las gestiones para la adquisición de las casas, pues el Ayuntamiento pide, allá por el mes de mayo, a los arrendatarios que allí tenían negocios, evalúen los perjuicios que el traslado les podía ocasionar ${ }^{5}$. De cualquier modo, lo cierto es que fueron fundamentalmente

\footnotetext{
${ }^{5}$ Las diferentes versiones que sobre esta cuestión han dejado huella escrita resultan bastante imprecisas e incluso contradictorias.

Isaac Díaz Pardo escribía en diciembre de 1981: «Durante la República se presentó en Santiago un contencioso entre el Banco de España - entonces sociedad mixta- y el Ayuntamiento. El Banco de España había comprado en la plaza de las Platerías - toda ella declarada entonces monumento nacional- la casa Espinosa de Domingo de Andrade... El Ayuntamiento, y en esto mi padre sí había influido, se opuso a las pretensiones del Banco de derribar ese monumento ofreciéndole en permuta por la casa Espinosa un terreno todavía mayor en la Senra. Una de las primeras cosas que hicieron en Santaigo al triunfar el alzamiento y en plena guerra civil fue cargarse la casa Espinosa de Domingo de Andrade, monumento nacional, en cuyo solar más tarde y con diversas vicisitudes se edificó el pastiche que vemos ahora en él.». (Testimonio de Isaac Díaz Pardo, que contaba entonces menos de 16 años, de los primeros momentos del alzamiento en Santiago de Compostela. En, Fernández, C.: El alzamiento de 1936 en Galicia. Sada: Ed. do Castro, 1982).

José Luis Cabo Villaverde, en sus breves comentarios sobre este edificio, repetía más o menos, sin llegar a citarlo, lo escrito por Díaz Pardo: «La idea surgió durante la República, al comprar el Banco de España la casa Espinosa, obra de Domingo de Andrade y monumento nacional, con el fin de derribarla y establecer su sede en Compostela con un inmueble de nueva traza. El Ayuntamiento se opuso al derribo, ofreciendo en permuta por la casa Espinosa un terreno todavía mayor en la Senra. Así estaban las cosas cuando estalló el alzamiento militar de 1936. Una de las primeras decisiones de las nuevas autoridades fue conceder el derribo...». (La Voz de Galicia: «Contrastes». 22-II-87. Ver tam-
} 
las nuevas autoridades franquistas quienes favorecieron, estimularon en lo posible e incluso agradecieron la instalación del banco en ese solar, probablemente en aras de una malentendida idea de progreso, confundida en estos primeros momentos de euforia y desconcierto con evidentes necesidades materiales de trabajo, ampulosa presunción y ansias de representativa monumentalidad física.

El permiso de demolición de las seis casas afectadas se concedió ya el día 30 de noviembre, tras un nuevo informe de José Banet en el que ahora se indicaban las normas a seguir y las líneas a las que debía ajustarse la construcción, prácticamente las mismas que tenían las casas derribadas, mínimamente rectificadas en las calles Gelmírez y Conga. Se acompañó además el permiso con el explícito agradecimiento, expresado por la Comisión de Fomento Municipal, hacia el Vizconde Alberto, consejero del Banco y uno de los principales impulsores de la obra, y hacia el Director de la sucursal, el señor Herranz, «... por haber acordado la adquisición de los inmuebles a derribar... y por haber acordado el derribo de estos inmuebles proporcionando así trabajo a los obreros en paro forzoso.»

Los primeros pasos, incluido el desalojo y derribo, se dieron con gran rapidez, pues la intención de todas las partes implicadas era, al parecer, solventar el grave problema del paro en Santiago y contribuir al «embellecimiento» y engrandecimiento monumental de la ciudad. En estos momentos aún a nadie se le ocurría poner siquiera en duda la validez del futuro proyecto.

bién: Cabo Villaverde, José Luis y Costa Buján, Pablo: Imaxe de Compostela. Unha cidade de pedra nas vellas fotografias. C.O.A.G. Santiago, 1991).

Celestino Sánchez Rivera, más conocido como Diego de Muros, colaborador de El Correo Gallego y anteriormente director de El Eco de Santiago, afirmaba, en uno de los muchos artículos que en 1939 escribió en torno al edificio, que el interés del Banco no fue desde el primer momento instalarse en la Plaza de Platerías. Si terminó alli fue — según el periodista - porque no pudo ubicarse en ninguno de los ocho o nueve lugares que previamente había escogido, fundamentalmente «por la desmedida ambición de algunos propietarios, que obligaron al Banco a desistir de sus propósitos en cada sitio». Continúa, en esta línea, afirmando que si la ciudad estuviese declarada Monumento Nacional en aquellos momentos, «a cuyo intento no solo no se ayudó, si no que se entorpeció, por la genuina representación del pueblo en 1935», no habrían podido comprarse y destruirse las anteriores casas. (El Correo Gallego, 19-3-1939).

Como puede ya suponerse, las implicaciones ideológicas que cada una de las anteriores versiones conlleva y su conocimiento no directo de la realidad de los hechos, hacen dificil cualquier intento de reconstruirla a partir de ellas.

"CUADERNOS DE ESTUdIOS GALLEGOS", Tomo XLII, Fascículo 107, Santiago 1995. 


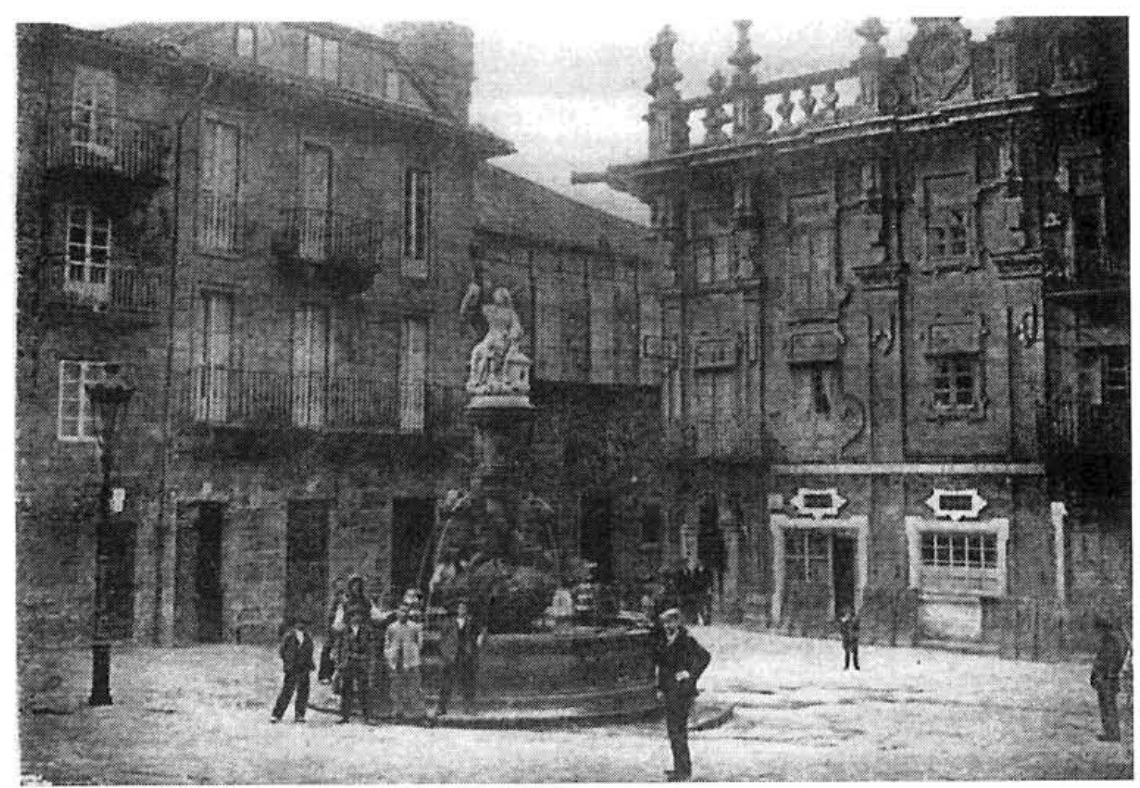

Aspecto que presentaba la Plaza de Platerías antes del derribo de las casas ubicadas en el solar adquirido por el Banco de España. (Foto: Hermógenes Garita).

Casi simultáneamente, al enterarse del derribo, el Presidente de la Comisión Provincial de Monumentos se dirige a la Academia de San Fernando para informar y lamentar el hecho ya consumado: la destrucción de la citada casa construida por Domingo de Andrade, que «... por la nobleza de la traza y el gran carácter santiagués completaba las líneas armónicas del sugestivo conjunto de la Plaza». De igual modo se dirige al Ayuntamiento el día 30 de julio de 1937, manifestando el mismo lamento y ordenando a la comisión municipal que someta a revisión de la Academia todo proyecto futuro para ese solar, tanto en lo relativo a alineación como a estilo ${ }^{6}$. Para que esta obligación llegara a conocimiento del Banco, una representación municipal, presidida por el propio Alcalde (en este momento, Manuel García Domínguez), visita en Burgos, en el mes de diciembre de ese mismo año, al señor Artigas, Subgobernador del Banco de España. Con

${ }^{6}$ El esquema de narración de los hechos que se sigue a partir de este momento, aunque con múltiples matices y añadidos, procede del informe redactado en Madrid por una comisión formada para el estudio del historial del proceso y resolución del mismo, firmado el día 11 de octubre de 1940.

"CUADERNOS DE ESTUdIOS GALLEGOS", Tomo XLII, Fascículo 107, Santiago 1995. 
posterioridad, la Comisión de Fomento del Ayuntamiento compostelano, en una carta de mayo de 1939 dirigida al Director de la sucursal, relataba de un modo muy peculiar el motivo que les había llevado a realizar aquella gestión, que convertían así en iniciativa propia:

«Visitó en Burgos esta comisión al señor Artigas... y le hizo conocer las distintas opiniones exteriorizadas en nuestra ciudad acerca de la línea que debía señalarse para el nuevo edificio. Y toda vez que al Ayuntamiento de Santiago le importaba grandemente que el nuevo edificio se situara en la línea más conveniente y que el proyecto respondiera grandemente al carácter de la plaza en que iba a construirse, rogole al Consejo del Banco de España que, antes de decidir sobre estos extremos de modo definitivo, consultara con la Real Academia de San Fernando acerca de ambos extremos...»

Y efectivamente el Banco consultó a la Academia el asunto, presentándole una memoria de proyecto y cuatro croquis en perspectiva con cuatro soluciones distintas de fachada, en el mes de febrero de 1938.

Pero, a partir de este instante, comienza a haber un distanciamiento entre el Ayuntamiento y la Academia que lleva a que las decisiones tomadas por cada una de estas instituciones respecto al Banco no sean conocidas por la otra. Se propicia así un marco de acción en el que el arquitecto encargado de construir la nueva sucursal, Romualdo de Madariaga, y la propia dirección de la misma, campan a sus anchas manejando la situación según su propia conveniencia, lo que en realidad provocó el que se llegase a un extremo final de tan difícil solución. Un buen ejemplo de ello lo encontramos ya en esa última carta mencionada, en la que se concluía:

"Aún cuando no hay noticia oficial de haberse cumplido esta promesa, la Comisión de Fomento tiene conocimiento por noticias particulares de carácter fídedigno que la consulta se hizo y fue respondida con que la alineación debía ser la de las casas, y que también concedió su aprobación al proyecto del arquitecto, señor Madariaga, al cual va a ajustarse la construcción del edificio.».

No sabemos cuales podían ser las tales «noticias particulares de carácter fidedigno», cuando la memoria descriptiva del proyecto había sido ya publicada en la prensa el 12 de marzo, concretamente en El Correo Gallego; pero lo cierto, es que la resolución de la Academia de San Fernando, 
recogida en un informe enviado al Banco el 3 de marzo de 1938, decía mucho más de lo que el Ayuntamiento conocía o, simplemente, había querido entender.

Por un lado, arremetía duramente contra los culpables de lo que ya no tenía solución ${ }^{7}$; por otro, se resolvía el asunto fundamental de la alineación, manteniendo la existente, y se fijaban unas normas que el arquitecto debía seguir en la formulación definitiva del proyecto:

«... que la nueva edificación sea obra de situación, volumen y aspecto lo más semejantes al edificio derribado... que se observe la anterior altura y se adopte para las fachadas una fórmula de composición que haga compatible el carácter de lo desaparecido con las necesidades de lo por edificar. Existen arbitrios y recursos admisibles y aconsejables; tales como buscar acomodo a servicios de última planta en construcción retranqueada, oculta a los puntos de vista asequibles; descender cuanto sea posible el nivel del piso de planta baja noble y reducir al mínimo tolerable la altura de los pisos diversos que integran la edificación. En la composición de fachadas debe prescindirse de elementos complejos en su forma o de excesivo volumen; de remates y adiciones ornamentales que conviertan un propósito de armonía en una desigual competencia con un monumento consagrado... reduciendo las alturas, simplificando las cornisas, armonizando salientes de jambas, impostas y pilastras; depurando la composición de la puerta de entrada principal y conviertiendo los huecos de planta baja noble en formas de trazado geométrico simple, de acuerdo con formas análogas inmediatas».

\footnotetext{
${ }^{7}$ En este sentido decía: «Examinados los antecedentes del caso, y conocidas las razones que motivan esta consulta a la Real Academia, debe ser antepuesta a cualquier manifestación, la del sentimiento que produce el hecho de que una autoridad municipal permita destruir innecesariamente la armonía arquitectónica y el pintoresco ambiente de un típico rincón monumental, de un carácter local inmejorable en una ciudad histórica, digna siempre del máximo respeto, singularmente de quienes tienen el deber inexcusable de velar por su ciudad, aunque no alcancen a tener la sensiblidad precisa para percibir la belleza de lugares como el destruido y ponderar el valor de todo orden que en ellos encierra. Debe elevarse dicho sentimiento a términos de enérgica protesta al conocer que, en el caso presente la autoridad municipal fue oportunamente advertida por entidades capacitadas para ello.».
}

"CUADERNOS DE ESTUDIOS GALlEGOS", Tomo XLII, Fasciculo I07, Santiago 1995. 
Como parecía lógico suponer, el proyecto surgido de estas recomendaciones debería haber sido nuevamente revisado por los miembros de la Academia; y sin embargo no fue así. Madariaga presenta ante la corporación municipal su solución definitiva, compuesta por varios planos y una memoria descriptiva, a principios de julio de 1939, sin que nadie, salvo José María Banet, quisiera darse cuenta de las irregularidades que contenía.

Previamente, el día 3 de enero de ese mismo año, una nota de prensa aparecida en El Correo Gallego hacía saltar, ante la opinión pública y de un sólo golpe, la chispa con la que se había de encender en los meses sucesivos la polémica que acabaría por contribuir a frustrar este primer proyecto para la sucursal del Banco de España en Santiago ${ }^{8}$. En febrero - -es decir, antes incluso de llegar al Ayuntamiento-, los planos del edificio, prácticamente acabados de recibir en la dirección de la sucursal, se exponían en un comercio de la ciudad. Era el segundo paso, la primera imagen que el público tenía, la desencadenante de una polémica que se desarrollaría desde posturas críticas muy dispares y de la que conviene hablar en otra ocasión, con más calma, como fiel exponente que fue de una importante faceta de la cultura de su tiempo.

Mientras que estos iniciales planos presentados por Madariaga llevaban la fecha de junio de 1938 (es decir, tres meses después de emitirse el informe de la Academia), sin embargo, la memoria descriptiva había sido firmada con posterioridad (el 22 de junio del año siguiente), pocos días

\footnotetext{
${ }^{8}$ La nota decía así: «El consejero del Banco de España, Vizconde de San Alberto, ha recibido un telegrama, en el que el Consejo de aquel establecimiento bancario le dice que ha acordado construir en Santiago un edificio para su sucursal, en el solar adquirido hace algún tiempo.

La subasta de las obras se celebrará en Burgos y en esta ciudad en muy breve plazo y seguidamente comenzarán los trabajos en los que tendrán ocupación numerosos obreros por ser el edificio de gran importancia.

Cuando conozcamos el dictamen de la Academia de San Fernando, así como el proyecto, daremos cuenta de ello a nuestros lectores y publicaremos fotografias de sus tres fachadas»».

Además de la felicitación, que entonces era unánime, al mencionado Vizconde de San Alberto, concluía diciendo con alivio de corredor de fondo, que tras veinticinco años de gestión por fin se harían realidad las aspiraciones del Banco de contar con un edificio propio, decoroso, en el que los funcionarios pudieran trabajar con holgura. (El Correo Gallego. Eco de Santiago: 3-1-1939).
}

"CUADERNOS DE ESTUDIOS GALLEGOS", Tomo XLII, Fascículo 107, Santiago 1995. 


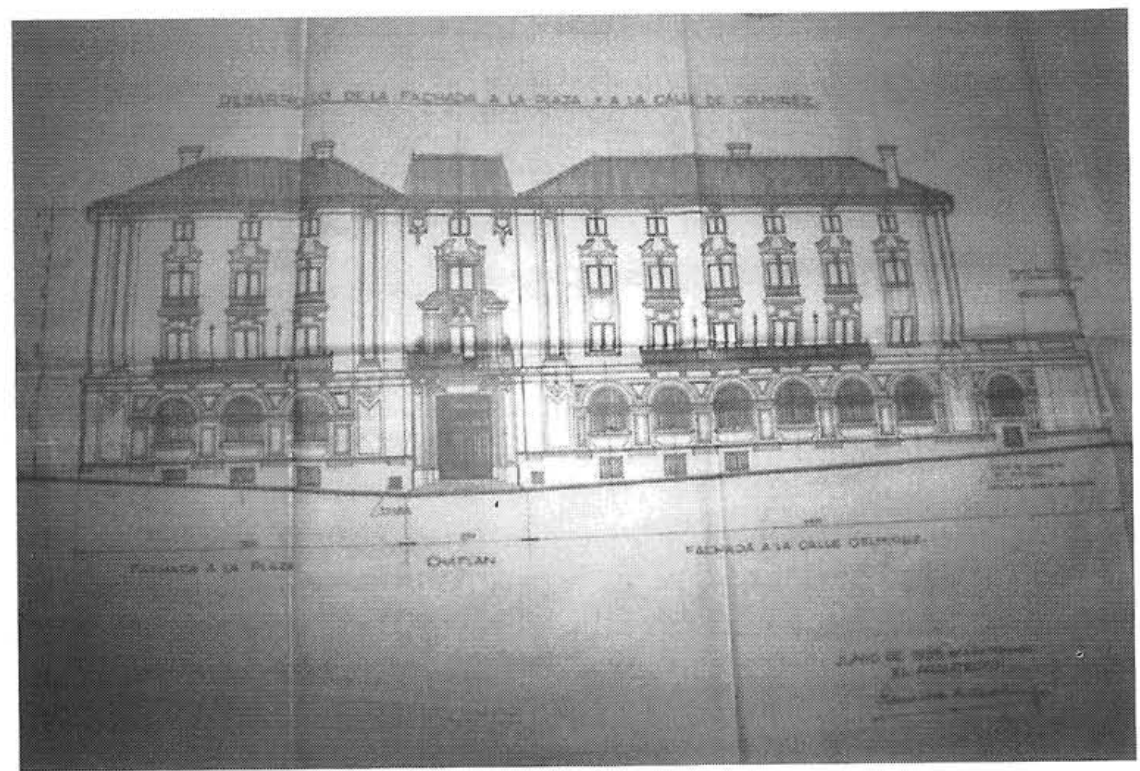

Fachada de la Plaza de Platerías, de la calle Gelmírez y chaflán.

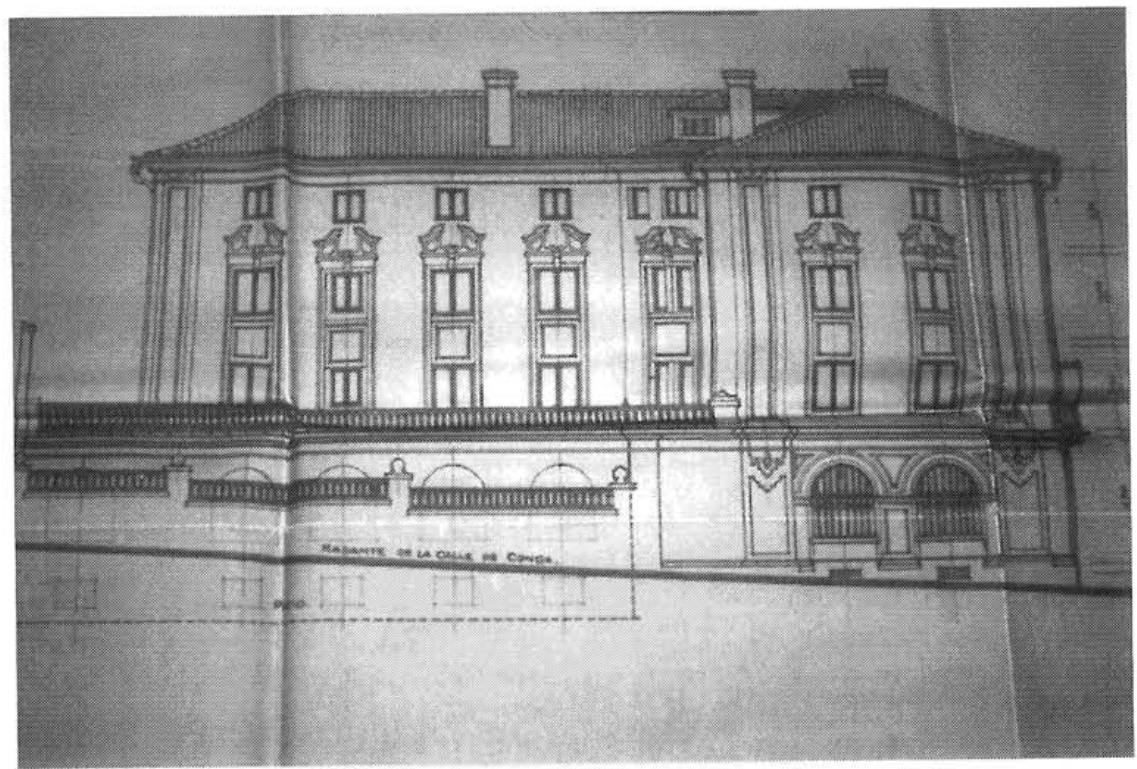

Fachada de la Calle de la Conga. 


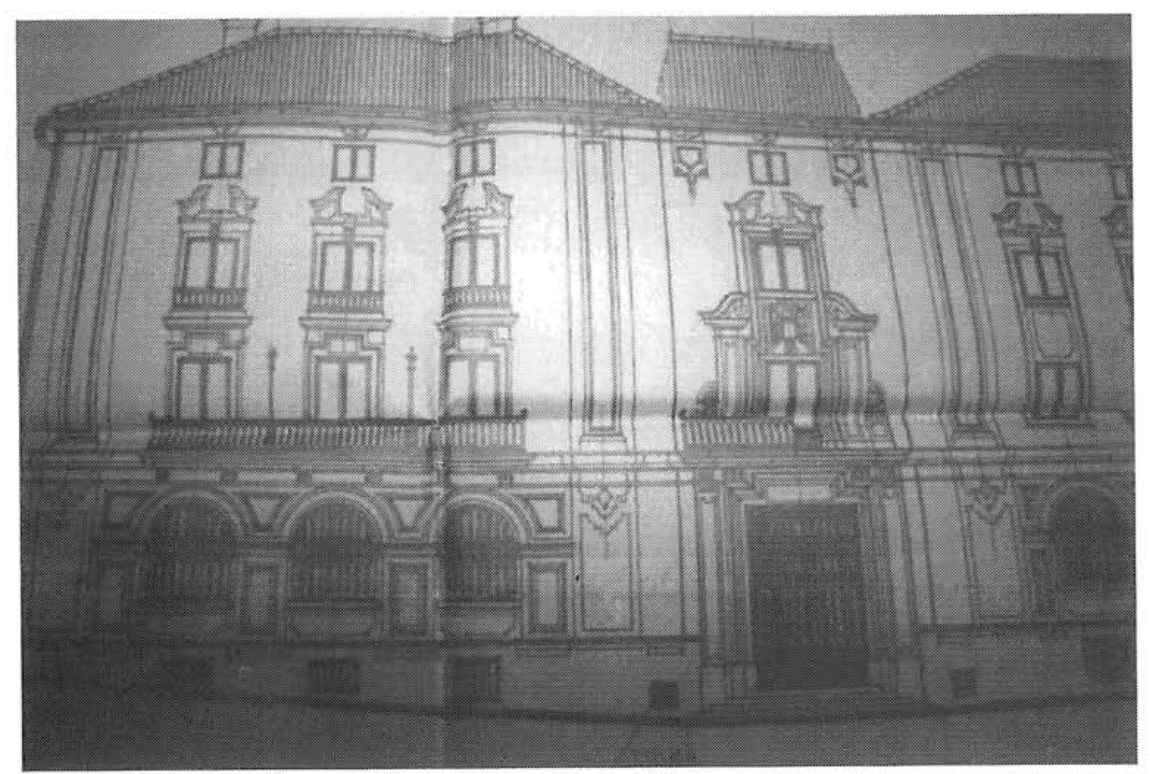

Fachada de Platerías y chaflán.

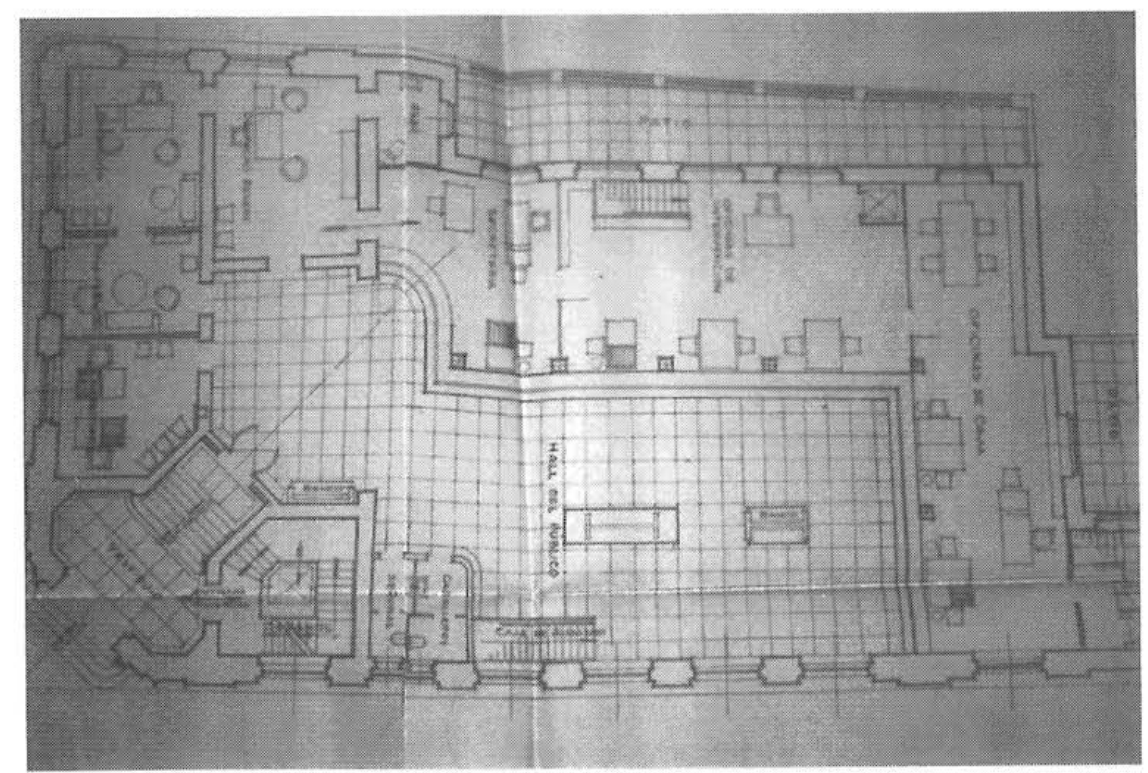

Plano de la planta baja. 


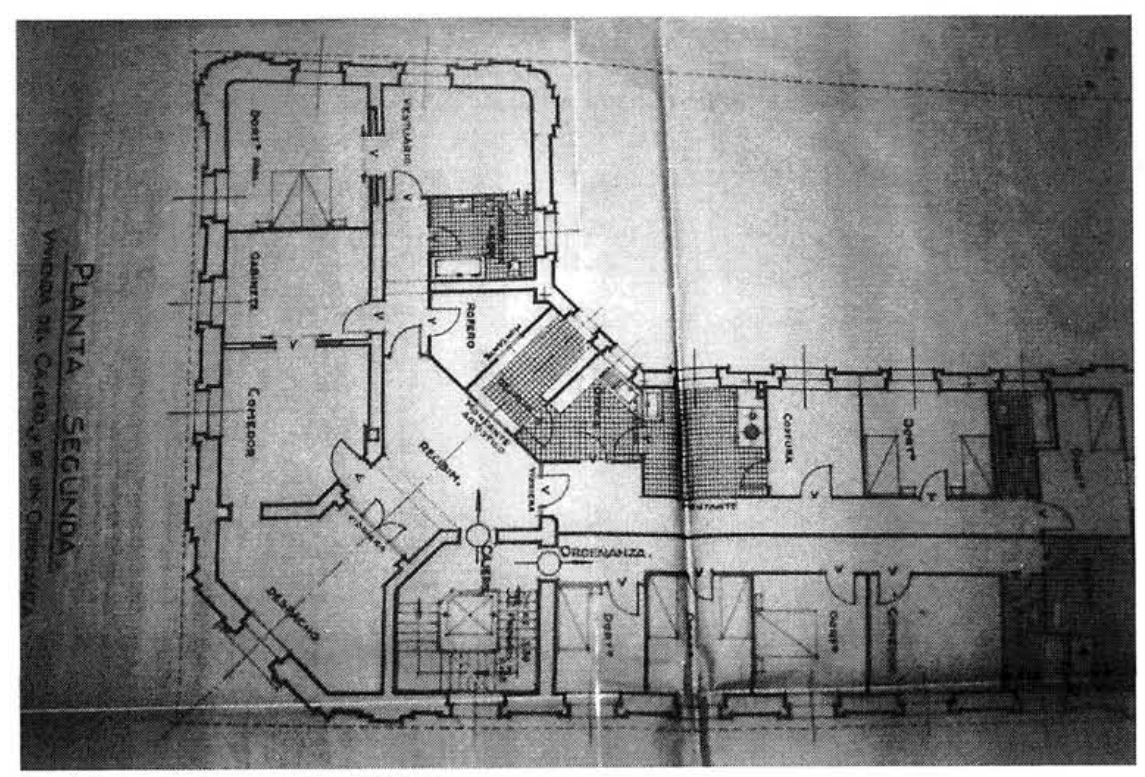

Plano de la planta segunda: viviendas.

antes de ser entregada en el Ayuntamiento. Se trataba únicamente de una justificación teórica que en realidad venía a ocultar una práctica ya consensuada, la de los planos, que seguramente los miembros de la administración municipal no llegaban a entender, y que, por otra parte, los de la Academia desconocían. De ahí el protagonismo que a partir de este momento va a tener, desde su cargo de arquitecto municipal, José María Banet.

Una versión prácticamente similar de esta misma memoria había sido integramente publicada meses antes - como ya hemos dicho- en El Correo Gallego (el 12 de marzo de 1939). Sin embargo, la fecha que en aquella ocasión presentaba era, como sucedía con los planos, la de junio de 1938, y estaba destinada en este caso al Consejo de Dirección del Banco de España, aún en Burgos. En el subtítulo de aquella publicación, inevitablemente leido hoy con ironía, se apuntaba: «Respeto a la armonía monumental en esta nueva obra arquitectónica, sin regateo a las exigencias del siglo». Y la memoria, en efecto, si se desconocía detalladamente el informe previo de la Academia, parecía confirmarlo, pues estaba plagada de medias verdades.

En efecto, desde el primer momento parecía atenerse al mencionado informe académico. Citaba incluso aquellos párrafos en los que se dictaban 
con exactitud las normas a seguir, pero casualmente se olvidaba de alguna frase: en concreto de aquella inicial que le aconsejaba el acomodo de los servicios de última planta en construcción retranqueada, $y$, fundamentalmente, de aquella otra, la única subrayada entre todas las consignas dadas, que le exigía la depuración de la composición de la puerta de entrada principal y la conversión de los huecos de planta baja noble en «... formas de trazado geométrico simple, de acuerdo con formas análogas inmediatas». Después, se dedicaba a enumerar las partes del edificio ajustadas a las normas académicas, para terminar asegurando que «... con el cumplimiento de todas las observaciones del dictamen emitido por dicha Institución, se ha redactado el actual proyecto».

El asunto de la alineación no precisaba por parte del arquitecto de excesivas justificaciones, pues contaba con el beneplácito de la Academia; y sin embargo, tal vez como medio de contrarrestar la opinión popular, la encajaba en una descripción de un Santiago de calles estrechas, interrumpidas por la continua presencia de soportales, sorprendidas por entrantes y salientes, perspectivas forzadas y gran variedad de formas en sus edificios. Todo ello la animaba — creía él — en un movimiento continuo, pero uniformado, acompasado por su armónica tonalidad y textura pétrea, en el que no desentonaría la nueva masa proyectada. Además consideraba muy positiva

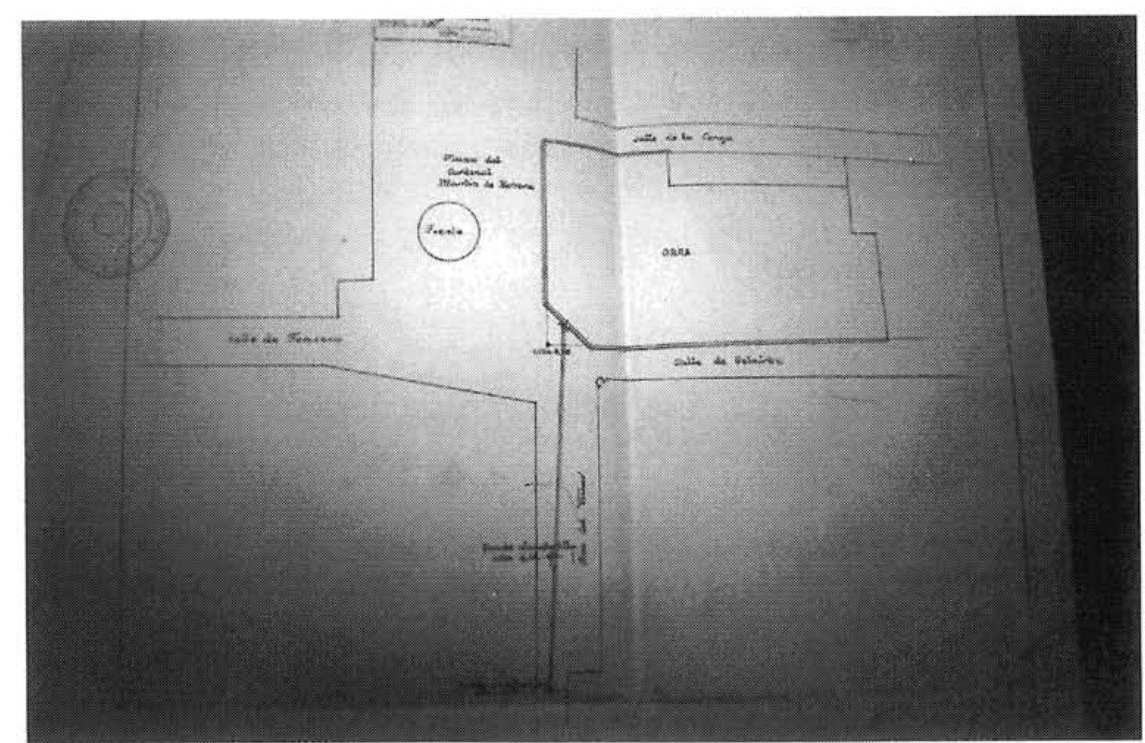

Plano de ubicación del edificio en el que se ven las alineaciones aprobadas por el Ayuntamiento tras el primer informe de la Academia.

"CUADERNOS DE ESTUDiOS GALLEGOS", Tomo XLII, Fascículo 107, Santiago 1995. 
la solución del amplio chaflán para favorecer la circulación desde la rúa del Villar y mejorar también desde ella la visión de la Torre del Reloj.

En realidad este proyecto no pasa de ser una muestra más del eclecticismo imperante; no era además especialmente diferente de los edificios que el Banco acostumbraba a instalar en otras ciudades. Madariaga, como arquitecto de la entidad, había asumido y aplicado en sus proyectos el principio fundamental que esta venía repitiendo desde hacía varios años en todo el país: el intento de integración del carácter funcional propio de este tipo de edificios, lo que condiciona sin posibilidad de variación su distribución interior, con soluciones de fachada que, recurriendo a esquemas de composición clásicos, académicos, y a peculiaridades propias de la correspondiente arquitectura local, desarrollara un adecuado grado de monumentalidad representativa. En este sentido, era pretensión habitual del Banco que sus inmuebles formaran manzana o se ubicaran en la confluencia de calles importantes, recurriendo entonces a un cuerpo de esquina achaflanado; que su vestimenta formal, además de contribuir a reforzar la sensación de sobria fortaleza que imponen sus contundentes y simétricos volúmenes (mediante el empleo, por ejemplo, de grandes pilastras y columnas clásicas), incluyera un buen número de elementos simbólicos; y que, asumiendo el regionalismo que animaba buena parte de los espíritus sensibles del momento, se respetasen las peculiaridades formales y especialmente materiales de cada tradición arquitectónica?

Era evidente que los responsables de la sucursal compostelana tenían especial interés en difundir entre los ciudadanos, con ilusionado orgullo e intención tranquilizadora, las características de un proyecto que, desde su complacencia, sin duda consideraban certero y adecuado. Sin embargo, lo que consiguieron al hacerlo público fue precisamente lo contrario: el día 5 de junio del 39 un grupo de personajes notorios de la ciudad ${ }^{10}$ —afirmando

\footnotetext{
"Saladina Iglesias, Lena: «Aportación al estudio de los edificios del Banco de España». Actas del V Congreso Español de Historia del Arte (II). Barcelona, 1984, pp. 185-190.

${ }^{10}$ Firmaban el escrito: Salustiano Portela Pazos (Deán de la Catedral), Jesús Rey Alvite (periodista), Segundo García de la Riva (propietario), Miguel Martínez Escalera (comerciante), Jacobo Martínez (propietario), Carlos Ruiz del Castillo (Rector de la Universidad), Manuel Remuñán (catedrático), Miguel Cabeza Anido (profesor universitario), Augusto Bacariza Varela (Director de la Caja Regional Gallega), Ángel Pedreira Labaide (inspector de la Caja Regional), Juan Varela Gil (médico), T. Batuecas (Vicerrector de la Universidad), Domingo Carro (comerciante), José Fernández Rofast (abogado), Felipe García Mirás (comerciante), Alejandro P. Labarta (comerciante), Ángel Rey Ga-
} 
hablar en nombre de todo el pueblo- - se unían para firmar una petición, entregada en el Ayuntamiento, en la que, si bien se contemporizaba con el resto de los problemas del edifico - en gran medida por la falta de conocimiento profundo de los mismos--, se plasmaba por escrito lo que era una insistente demanda de una parte de los santiagueses: el retraso de la línea de edificación ${ }^{11}$. En sus párrafos más importantes la carta decía lo siguiente:

«... quiso (el Banco) en su noble deseo de embellecer la ciudad de Santiago, emplazar en esta admirable plaza su nuevo edificio para sustituir un lienzo mudo de construcciones vulgares, con los muros de un nuevo palacio, digno del monumental marco arquitectónico.

El afán del Banco de España cristalizó en un hermoso proyecto, debido al ingenio del arquitecto Madariaga, que ha sido expuesto al público y obtenido de la Academia de San Fernando el beneplácito y permiso oficial. El sentimiento de aprobación por parte del pueblo de Santiago ha sido bien claro y manifiesto y el agradecimiento a la entidad

llardo (comerciante), Francisco Asorey (escultor), Vicente Latorre (propietario), Bernardo Louro (párroco), Juan Luis López (pintor), Marcelino Blanco (banquero), Manuel López Garabal (pintor), Jorge de la Riva (comerciante), Augusto Otero Martínez (joyero), José Gómez Fernández (médico), Román López y López (comerciante), Argimiro Silva (médico), Fernando Alsina (profesor de la Universidad), José Puente Castro (médico), Antonio Novo Campelo (catedrático), Manuel Pérez Esteso (banquero), Jerónimo Coco Morante (canónigo), Manuel Capón Fernández (Rector del Seminario), Fernando Peña Vicente (Vicario de la Archidiócesis), Claudio Rodríguez (canónigo), Nicolás Ruíz Rueda (canónigo), Cándido García (canónigo), Emilio González Vila (canónigo) y Ramón Fabeiro Vigo (Presidente de la Archicofradía del Apostol), Enrique García Ramos (comerciante), M. Devesa (médico), Avelino Cimadevila (comerciante), Manuel Rodríguez Suárez (canónigo), José Limia Rodríguez (sacerdote), Ventura Cañizares (canónigo), Robustiano Sández (canónigo).

Obsérvese la composición social y profesional del grupo y será fácil darse cuenta de porque su opinión fue tan respetuosamente atendida y acogida.

"El hecho de que parte de los ciudadanos firmara un manifiesto y proclamase públicamente su oposición a determinadas intervenciones en la ciudad no era algo nuevo. Algún tiempo antes, en torno al tema de la conservación de las fuentes públicas, muchos compostelanos habían firmado un manifiesto defendiendo la conservación y armonía de la ciudad. (El Compostelano: 24-2-39, pág. 1). Y anteriormente, en un caso en el que también había intervenido la Academia, el pueblo había conseguido con sus protestas que se retirara de la Plaza del Obradoiro la estatua de Montero Ríos. (El Correo Gallego: 15-2-39, pág. 7).

"CUADERNOS DE ESTUdIOS GALLEGOS", Tomo XlII, Fascículo 107, Santiago 1995. 
Banco de España, infinito, por la preocupación y defensa de los intereses artísticos de Compostela.» ${ }^{12}$

El único problema que realmente se veía al edificio era el de la línea, «... y aquí también - decían - hay que reconocer que el pueblo de Santiago se ha pronunciado de manera clara y precisa, reconociendo que retirando la línea hasta la del palacio de la Quintana, quedarán en descubierto nuevas bellezas, una mayor visualidad de la escalinata que da acceso a la catedral y de la Torre del Reloj en su porción inferior, sin hacer perder a la plaza su carácter íntimo y recogido, principal encanto de la misma.

Este es el sentir del pueblo; esta es la aspiración general y popular que es preciso admitir porque está en todos los pensamientos y en todos los espíritus... Y como prueba del acierto en este sentir popular, diremos que ilustres personalidades del mundo de las artes y distinguidos arquitectos comparten la misma opinión, en diversas ocasiones manifestada.».

Finalmente, en su afán de no causar ningún perjuicio al Banco, se comprometían los firmantes a organizar una suscripción pública para sufragar los gastos que estas reformas podían entrañar, «... y que sería una verdadera demostración práctica del interés y del ansia popular que existe en este punto de la nueva alineación donde se construya el palacio destinado a Banco de España.».

El Ayuntamiento se dirigía el día 17 de ese mismo mes al Banco, para hacerle conocer este escrito, reconociendo el perfecto derecho que tenía a no cambiar sus planes, pero esperando una respuesta positiva, que, según su criterio, debería ser nuevamente presentada ante la Academia de San Fernando.

Exactamente un mes después, el Consejo General del Banco de España comunicaba al Ayuntamiento, con las buenas palabras habitualmente empleadas en estos casos y escudándose en el veredicto de la Academia, que tal petición era de imposible cumplimiento. Era la primera vez que el Banco mostraba abiertamente su posición, su falta de flexibilidad, y en realidad fue el primer mal paso que provocó su tropiezo.

En gran medida laconfrontación se inició al enviarse una copia de aquella petición popular a la propia Academia, acompañada de una propuesta para que se formase una comisión de académicos que estudiase la problemática

${ }^{12} \mathrm{Si}$ se estudia la polémica desarrollada en la prensa, se observa, sin embargo, que los sentimientos de aprobación o desaprobación no eran tan unánimes como este escrito pretendía. 
sobre el terreno. Esta vez la petición sí fue atendida y, como consecuencia de ello, tras la visita de la comisión creada al efecto, la Academia envió al Subgobernador del Banco de España, con fecha de 28 de octubre del 39, un nuevo informe, del que no llegaría a tener en ningún momento noticia el Ayuntamiento de Santiago.

El nuevo informe ${ }^{13}$, tras reconocer que al anterior no había tenido en cuenta aspectos «difíciles de prever» que ahora modificaban el punto de vista y reconociendo también las dificultades que para el Banco estas modificaciones supondrían, reconsideraba el problema, «suscitado por determinadas instancias elevadas al Alcalde del Ayuntamiento de Santiago por entidades y personas representantes del sentir popular compostelano», y dictaminaba lo siguiente:

«(Consideramos necesario)... obtener del Banco de España... que retire la línea de su fachada principal a la que resulta de prolongar el Palacio de la Quintana; de manera que resulte totalmente diáfana y limpia de obstáculos la perspectiva magnífica de la Torre del Reloj desde la Rúa do Vilar; insistiendo sobre dos puntos que considera fundamentales a más de lo expuesto: de una parte la conveniencia de seguir, como sea posible, la traza de algún edificio inmediato a la plaza, de tal modo que las formas del nuevo edificio armonicen con algunas de las ya existentes, del mismo modo que las piedras empleadas en sus fachadas se ajusten igualmente en color, bien sea por su natural condición o por imitación discreta, a la pátina que hoy cubre, de manera uniforme, todas las fachadas del resto de la plaza.».

Por otra parte y simultaneamente, desde su cargo municipal, José María Banet, comenzó a poner serios reparos a la globalidad del proyecto, aún desconociendo, como todo el Ayuntamiento, el cariz que estaba tomando el asunto por la otra vía de intervención, la de la Academia.

Como respuesta a la petición de permiso para comenzar las obras de construcción ${ }^{14}$, el arquitecto municipal recomendó (el 15 de julio) que éste

\footnotetext{
${ }^{13}$ Redactado por la Sección de Arquitectura y aprobado el día 9 de octubre en reunión plenaria de la Academia.

${ }_{14}$ Petición realizada por Vicente Herranz el 20 de junio de 1939, es decir, algunos días antes de que se presentase en el Ayuntamiento la memoria y los planos del proyecto, lo cual haría que se retrasase su aprobación. Esta es una muestra más del total caos en el que se estaban llevando a cabo todas las gestiones y la falta de conexión entre todas las partes implicadas.
}

"CUADERNOS DE ESTUDIOS GALLEGOS", Tomo XLII, Fascículo 107, Santiago 1995. 
se sometiese a una nueva revisión por parte de la Academia antes de conceder la licencia. El Ayuntamiento, con cierto retraso - -en el mes de noviembre-, pide a Banet que el mismo realice un informe al respecto. Su respuesta, fechada el día 18 de ese mismo noviembre, enumera lo que consideraba eran los desaciertos fundamentales en el proyecto y que le llevan nuevamente a solicitar que se pida la aprobación de la Academia, algo en lo que insistía en todos sus informes desde ahora:

En primer lugar, no cree acertada la construcción del amplio chaflán, que medía 6,50 metros, por entender que no armonizaba con el trazado en planta de la plaza, dominada por los ángulos rectos.

Tampoco creía acertada la composición de la fachada, en la que dominaban las verticales, por entender debiera haberse adoptado una composición a base de horizontes que condujesen a la nota culminante de la plaza: la catedral.

Finalmente apuntaba:

«El barroco empleado en las fachadas entiendo que no armoniza con el carácter de la arquitectura de la plaza, ni aún con el de la de Compostela. Dificultan, a mi juicio, la armonía, además de la composición general, determinados detalles, tales como la composición de la portada enlazada con los huecos de las plantas superiores, formando un conjunto de 14 metros de elevación; el enlace de los huecos superpuestos de las plantas primera y segunda; los medios balcones de hierro en los huecos de la planta segunda, etc., etc...»

De este modo echaba por tierra la validez de todo el proyecto, del que además afirmaba que copiaba en su memoria parte de las normas dadas por la Academia pero sin someterse, a su juicio, a ellas.

Pero el Ayuntamiento no tomaría su informe en consideración. Así, la Comisión de Fomento aprueba la concesión del permiso el 30 de noviembre, después de señalar que el arquitecto municipal (nunca se utilizaba su nombre para referirse a él) no aportaba pruebas feacientes para fundamentar su afirmación. Preferían creer los razonamientos de la memoria de Madariaga y del Consejo del Banco de España. Además — decían- «la gran mayoría de los santiagueses expresaron su parecer de que el proyecto del señor Madariaga no desentona con el carácter arquitectónico de Compostela y así lo estima también la Comisión Municipal de Fomento... 
después de estudiar el proyecto y después de haberse asesorado de personas de reconocida capacidad y de una notoria sensibilidad artística.». ${ }^{15}$

Vuelven finalmente, antes de terminar, a remitirse a «fuentes fidedignas», para decir que saben que el proyecto sufrirá pronto algunas variaciones, por lo cual estimaban conveniente hacer conocer al Banco, por si les fuera útil alguna de sus indicaciones, el informe del arquitecto municipal. En esta ocasión sí que se sabía perfectamente en el Ayuntamiento cuales eran las variaciones que se iban a realizar, puesto que el día 15 de ese mes de noviembre - mientras Banet realizaba el aludido informe crítico y se decidía la concesión de la licencia de obras- el Alcalde había pedido a Madariaga un plano de la fachada del edificio, para tener mayor información, o, tal vez, para conocer esas supuestas y necesarias variaciones (si es que ya había oído hablar de ellas), recomendadas tanto desde Santiago como desde la propia Academia.

En efecto, la respuesta de Madariaga, del 20 de noviembre, incluía un nuevo plano de escala $1 / 20$ en el que los cambios se hacían más que evidentes (hablaremos sobre ellos inmediatamente), y en la que además se decía: «... podrá apreciar el celo puesto en conseguir las normas marcadas por la Real Academia que perfectamente concretadas me sirvieron de guión, primero para redactar el proyecto y que sigo teniendo en cuenta en el estudio

${ }^{15}$ Cuando la Comisión creada en Madrid, encargada del seguimiento del caso, emita su informe del 11 de octubre de 1940, hará referencia al proyecto inicial presentado por Madariaga de este modo:

«Este proyecto, a juicio de esta comisión, no cumple las indicaciones del informe emitido por la Academia, por cuanto no se ajusta exactamente a la alineación, estableciendo un chaflán que enlaza las alineaciones de las fachadas de la calle Gelmírez y la Plaza de las Platerías, que, por otra parte, dada su importancia, no armoniza con el trazado en planta de esta plaza, en la que dominan los ángulos rectos. Respecto al volumen tampoco se atiene a lo prescrito por la Academia por cuanto el filo de su cornisa se eleva sensiblemente 2'50 metros sobre el de la casa más alta de las derribadas.

La manera de trazar las fachadas tampoco está de acuerdo con el citado informe, pues dispone un sistema de huecos enlazados verticalmente y coronados por un a modo de frontones partidos que en nada armonizan con el carácter del lugar».

En cuanto a la reacción del Ayuntamiento, la disculpaba esta comisión por el hecho - dice-de que este consideraba que el proyecto respetaba lo dictado por la Academia, no creyendo que la introducción del chaflán tuviera importancia decisiva. En lo referente a la altura, sin embargo, si achacaban el desliz a la ingenuidad y la ignorancia en la materia de los miembros de la corporación municipal, que no había sabido leer el proyecto hasta que la realidad puso de relieve su ilegalidad.

"CUADERNOS DE ESTUDIOS GALLEGOS", Tomo XLII, Fascículo 107, Santiago 1995. 


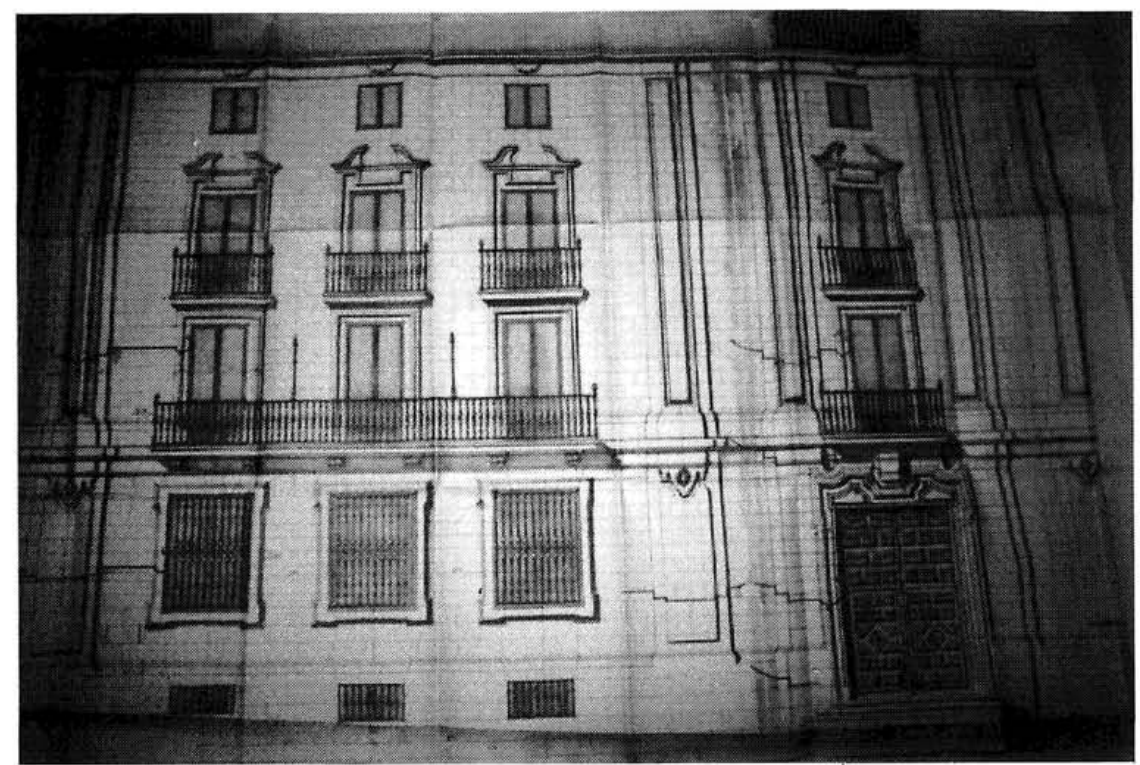

Plano de la fachada (escala 1/20), probablemente realizado en septiembre de 1939, en el que se aprecian los cambios que se pretendía introducir respecto al proyecto inicial.

de los planos de detalle. He prescindido en absoluto de obtener efectos de suntuosidad como los que se lograban con alguna de las soluciones presentadas en el anteproyecto y en cambio los planos de obra entonan de modo absoluto con la casa inmediata que da vuelta a la plaza del Cardenal ${ }^{16}$; tiene el nuevo edificio la misma base de composición, sus molduras en pilastras, jambas, cornisas, cerrajería, etc. son una reproducción exacta de los perfiles existentes en aquella; es decir, puede considerarse como una prolongación de ella sin elemento alguno extraño.

La portada está inspirada, con alguna mayor sencillez, en una existente en convento muy cercano y la factura de su puerta tiene semejanzas con la de la Iglesia de Salomé... No ha sido para mi fácil tarea conseguir propia estimación de mi trabajo con las limitaciones impuestas... he querido ser el de más respetuoso criterio con lo que dejaron trazado nuestros antepasados...».

${ }^{16}$ Nombre oficial que entonces tenía la Plaza de Platerías: Plaza del Cardenal Martín de Herrera.

"CUADERNOS DE ESTUDIOS GALLEGOS", Tomo XLII, Fascículo 107, Santiago 1995. 


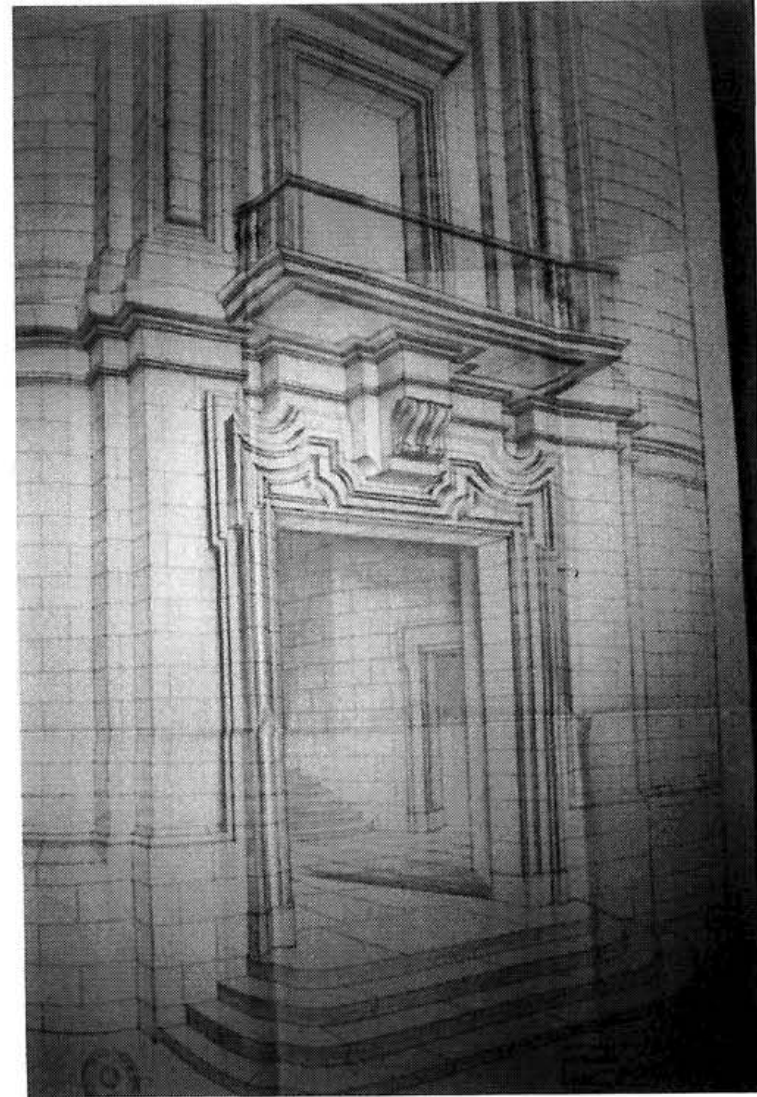

Dibujo en perspectiva de la portada
La limitada paciencia de Madariaga, quien como arquitecto principal del Banco en estos años estaba probablemente acostumbrado a plantar sus seriadas soluciones en el lugar asignado, comenzaba a desbordarse.

Una vez iniciadas las obras, estas sufrirán continuas paralizaciones. La primera, debida a que los cambios que se iban a acometer en la fachada del edificio, ya conocidos por todos, no fueron precedidos de la necesaria petición de permiso oficial. Este hecho motivó la suspensión de las obras el 23 de enero, tras un informe de Banet en el que denunciaba que las obras no se ajustaban al proyecto inicial aprobado por el Ayuntamiento.

La inicial respuesta de Madariaga, además de aportar nuevos planos de detalle, llevaba cierta carga de indignación, pues consideraba que las variaciones ya anunciadas estaban suficientemente aclaradas y que no había habido ninguna otra que el considerase necesitada del permiso del Ayuntamiento. Sin embargo, lo cierto es que la comunicación de cambios no había seguido los cauces oficiales apropiados y Banet ya no estaba dispuesto a dar ninguna facilidad a los constructores, por muy acertadas que fuesen las reformas emprendidas y por mucho que peligrasen, como afirmaba Madariaga, los puestos de trabajo.

"CUADERNOS DE ESTUDIOS GALLEGOS", Tomo XLII, Fascículo 107, Santiago 1995. 


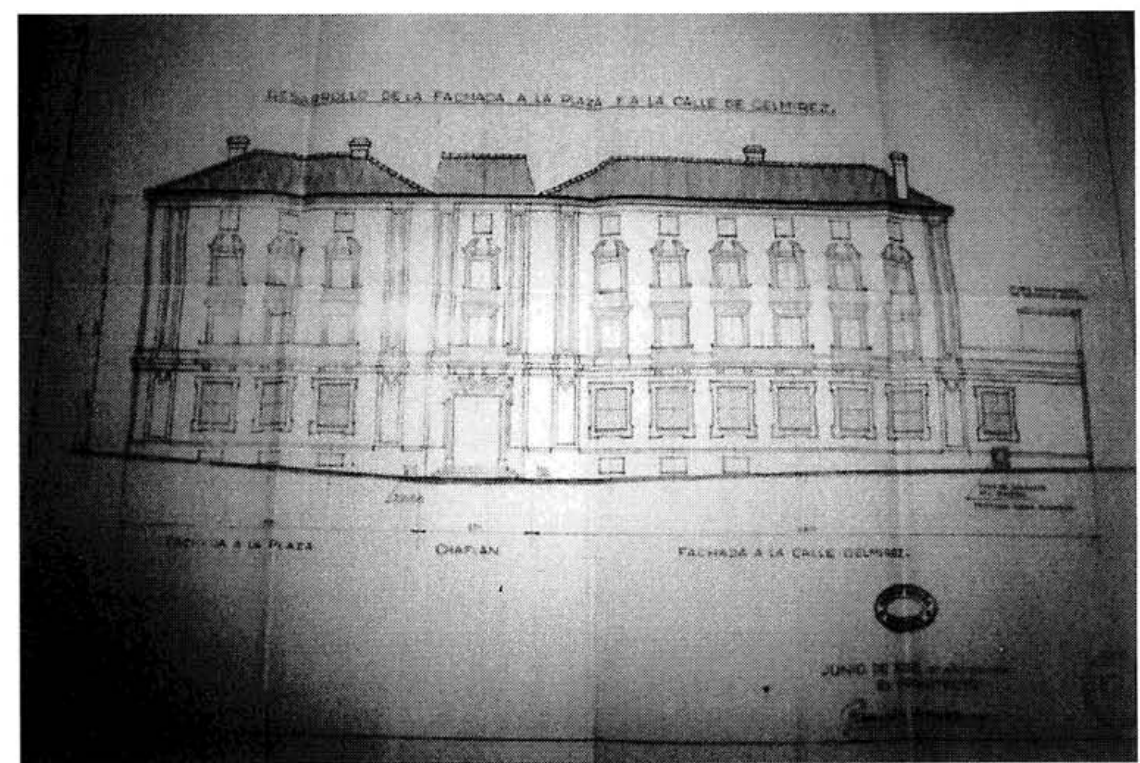

Plano realizado en junio de 1938 en el que se contienen las reformas que Madariaga introdujo en el proyecto meses después.

El 8 de marzo el Ayuntamiento recibía un nuevo plano (fechado ya en septiembre de 1939) en el que de nuevo se recogían en detalle las reformas, introducidas — según se decía - por iniciativa del propio Madariaga ${ }^{17}$. Se especificaba ahora que se realizaban para mejorar la belleza del primitivo proyecto y que consistían en la sustitución de las antiguas ventanas de medio punto de la planta baja por otras de forma rectangular, más senci-

${ }^{17} \mathrm{La}$ fecha del plano presentado, anterior al segundo informe emitido por la Academia (octubre del 39) hace pensar que efectivamente las reformas habían sido decididas por iniciativa del propio Madariaga. La existencia en el archivo municipal — sin que sea posible determinar el momento en que llegó allí- de un plano de todas las fachadas con estas mismas soluciones, simplificadas respecto al proyecto presentado inicialmente, y fechado como este último en junio de 1938, hacen indudable el hecho de que el arquitecto barajó durante todo el proceso esas dos posibilidades estilísticas, decidiéndose en un primer momento por la más suntuosa y rectificando después al asumir la versión, digamos, más austera y simplificada. Esta última puede ser entonces una respuesta más respetuosa a las normas dictadas por la Academia en su primer informe, aunque adoptada tardíamente, o una acomodación a los dictados teóricos que fundamentalmente desde este año de 1939 venía imponiendo el pensamiento arquitectónico del nuevo régimen.

"CUADERNOS DE ESTUDIOS GALLEGOS", Tomo XLII, Fascículo 107, Santiago 1995. 
llas; es decir, se cumplía en realidad una de las normas que la Academia había dado en su primer informe. El mismo día José Banet emitía un informe favorable a las reformas por considerar que se ajustaban mejor, por su sencillez, a las características de la plaza y a las normas de la Academia. Aprovechaba además la ocasión para insistir de nuevo en someter a estudio de aquel organismo el proyecto y sus variaciones, con el que por lo demás, a nivel global, seguía sin estar de acuerdo. También el mismo día la Comisión de Fomento aprobaba las reformas, teniendo en cuenta el informe - esta vez sí- del arquitecto municipal.

Desde este momento la obra progresó con rapidez y sin más obstáculos por parte del Ayuntamiento, aunque durante poco tiempo, pues cuando estos reaparecieron, impuestos desde otras instituciones, fueron ya contundentes.

La raíz de este insuperable obstáculo quedaba ya un poco atrás, en el instante en que las modificaciones sufridas por el proyecto inicial llegan a conocimiento de los académicos, por intermedio de la Dirección General de Arquitectura. La Academia, el 5 de febrero de 1940, toma el acuerdo de dirigirse al Subgobernador del Banco de España para que urgentemente informe sobre este asunto y al Director General de Arquitectura, Pedro Muguruza, para que si lo creía pertinente, mientras no llegaban las explicaciones del Banco, suspendiera las obras de modo cautelar ${ }^{18}$. El asunto pasaba así a estar bajo el control directo de las más altas instancias, en el terreno arquitectónico, del nuevo régimen.

La narración de sucesos del informe que posteriormente emitirá la comisión designada desde el Ministerio, da aquí un gran salto hasta el mes de octubre de ese mismo 1940. Antes, sin embargo, se encaja la mencionada carta del 7 de septiembre enviada por el Director General de Bellas Artes, en la que se contenía la reprimenda al Alcalde reproducida al principio de este estudio. Junto a ella, figuraba la orden de constitución de aquella comisión $^{19}$, encargada de resolver el problema en un plazo improrrogable de diez días, en el que debían de viajar a Santiago e informar al Ministerio.

\footnotetext{
${ }^{18}$ Por lo que se deduce del posterior informe de la comisión nombrada por el Ministerio, parece que no llegó a decretarse la suspensión. Además, al no ser ya competencia del Ayuntamiento este dato no se refleja en sus archivos.

${ }_{19}$ De la que formarían parte un representante de la propia Dirección General de Bellas Artes, otro de la de Arquitectura, uno de la Real Academia de Bellas Artes de San Fernando y, finalmente, el propio Alcalde de Santiago.
} 
El grupo, que fechó su dictamen el día 11 de octubre, estudió el proyecto definitivo y comprobó sobre el terreno el estado de las obras, coincidiendo en su informe con la idea de que, en lo relativo al tratamiento de huecos de la fachada, las variaciones mejoraban lo aprobado. En lo referente al volumen, sin embargo, se denunciaba que la altura de la estructura construida superaba en más de dos metros la del proyecto aprobado y en más de 4'50 la determinada por la Academia en su primer informe. Como consecuencia de todo ello, se concluía lo siguiente:

«Esta comisión acuerda hacer suyo, en líneas generales, el informe emitido por la Academia (23 de octubre de 1939) concretando su dictamen en los siguientes extremos y salvando su voto el Alcalde de Santiago en cuanto se oponga a las consideraciones que como del Ayuntamiento o suyas se expresan con anterioridad, principalmente en cuanto a alineación del edificio, cuestión en Santiago muy discutida y en todo caso discutible.».

Los extremos aludidos eran:

I. Alineación de la fachada: debía retrasarse la línea de la fachada de Platerías hasta seguir la misma que presentaba la inmediata casa de la Quintana, prescindiéndose de todo chaflán y presentando sus ángulos aristas vivas como las que mostraba aquel edificio.

II. Volumen: En cuanto a la fachada de Platerías, su altura debía ser análoga a la que tenían las casas derribadas — y especificaba - «... es decir, que el filo de su cornisa estará a una altura intermedia entre la citada casa (de la Quintana) y la de la casa del Deán, pues de esta manera se acusa perfectamente el desnivel formado por los dos planos de la plaza acentuando así la importancia de la monumental escalinata... Para ello podrá suprimirse la última planta con objeto de reducir en lo posible los perjuicios que se ocasionen a la entidad propietaria por el avanzado estado de la obra».

III. Tratamiento de fachadas: «La disposición debe acusar al exterior tres series de huecos correspondientes a otros tantos pisos, aparte de los del semisótano, reduciendo en lo posible la de la planta baja (oficinas del Banco) para mantener la conveniente proporción de huecos y macizos en armonía con la tranquilidad y escala de la plaza. Respecto al tratamiento de la cornisa, imposta, recercado de huecos y demás elementos decorativos, deberá atenerse en lo posible a los correspondientes elementos de la inmediata casa de Varela (Quintana)».

"CUADERNOS DE ESTUdios GALLEGOS", Tomo XLII, Fascículo 107, Santiago 1995. 
Tras este estricto recetario de normas a seguir la comisión exigía además que el proyecto resultante fuese revisado por el propio Ministro de Educación Nacional, quien se encargaría, previos los asesoramientos que estimase oportunos, de dictaminar la resolución definitiva. «Entretanto - terminaba - procede que sean suspendidas las actuales obras en curso.».

Esta nueva interrupción se prolongó durante cinco años, pues hasta marzo de 1945 no se realizaron los planos del nuevo proyecto, teniendo su memoria que esperar a ser redactada hasta junio de aquel mismo año. Firmaba entonces aquel proyecto, además de Madariaga, tal vez ya incapaz de someter sus iniciales pretensiones a una nueva depuración, Luis Menéndez Pidal, otro de los arquitectos de la entidad.

El estado de las obras durante la espera hasta el 45 , podemos conocerlo a través de una fotografía parcial de la fachada aparecida en 1943 en la revista Finisterre ${ }^{20}$, concretamente como ilustración de una entrevista realizada a Federico García Sanchiz, a quien se encumbraba como «portavoz del "santiaguismo" $>\rangle^{21}$. Se incluían, además de la fotografía, los vehementes comentarios que García Sanchiz dedicaba al edificio del Banco de España. El diálogo discurría más o menos de este modo:

«—Pero al par — decía el "charlista" introduciendo él mismo el temahay que preocuparse de Compostela, la portentosa Compostela, relicario que ha de ser digno de sus reliquias. Le supongo enterado de...

- ¿Qué?...

- De que se hallaba en peligro de horrendas profanaciones, y digo se hallaba porque está en vías de arreglo la mayor de todas ellas: el nuevo edificio del Banco de España, tremendo error, sin excusa posible. Puedo asegurar que va a repararse el daño. El Gobierno y el Banco, de consuno, han decidido salvar la difícil situación creada por un desliz que no sé si llamar arquitectónico.

\footnotetext{
${ }^{20}$ Federico García Sanchiz, portavoz del «santiaguismo». Finisterre, $\mathrm{n}^{\circ} 3$, Pontevedra, noviembre de 1943, pp. 28-29.

${ }^{21}$ Se presenta además en esta entrevista a García Sanchiz como el «creador indiscutible de las charlas líricas», género oratorio con el que vertía todas aquellas inquietudes propias que consideraba podían interesar a un público que llenaba, para oir su voz «cálida, acariciadora y persuasiva», locales de variado tipo, tanto en Galicia como fuera de ella. Se anunciaba ya aquí, en concreto, una gira que, con el tema de "Compostela y el Santiaguismo», recorrería Valencia, Barcelona, Madrid y las grandes ciudades hispanoamericanas. Ciudades, en las que es de suponer, se repetirian los rugidos que emitía ante la visión de la sucursal del Banco de España.
} 
- ¿Cómo?

- Ya se verá. Perdóneme que por ahora no pueda ser más explícito.

Pero, en suma, respondo de que el tumor será extirpado.

- ¡Magnífico!.»

Y ya casi al final, al caminar por delante del edificio, se recrudecían los ataques, narrados y compartidos así por el entrevistador (E.C.):

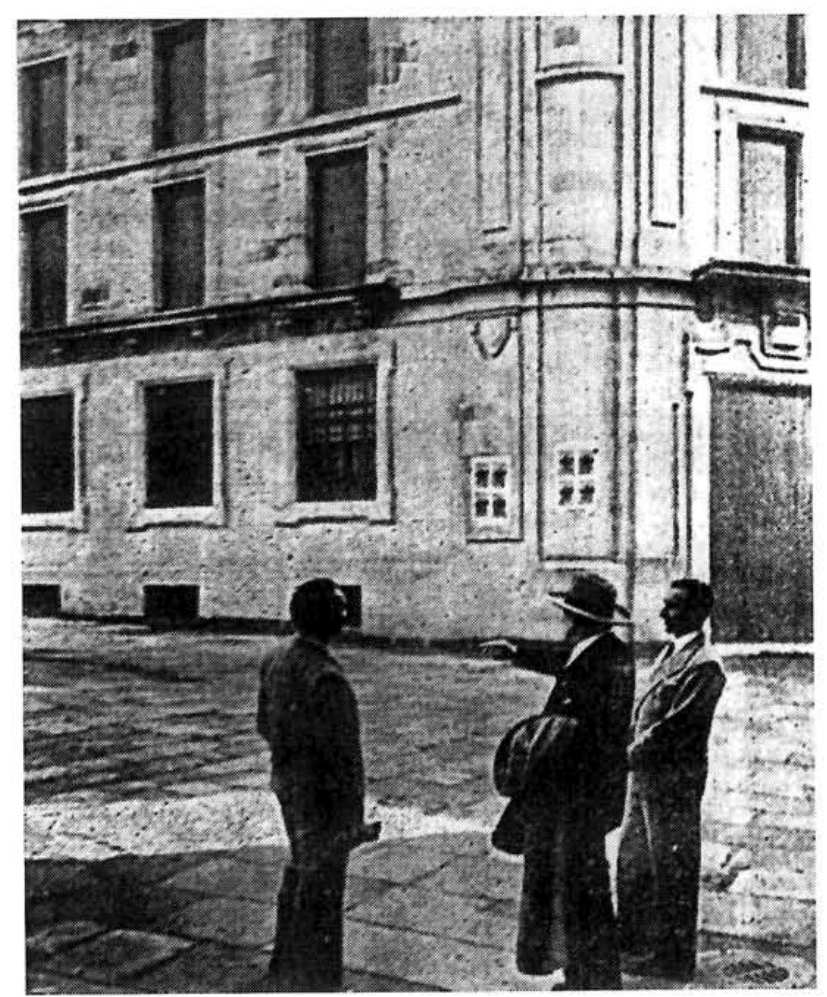

(Foto: Finisterre, noviembre 1943). En su pie se decía: «"Respondo de que el tumor será estirpado", afirma García Sanchiz a nuestro Director, señalando con además fulminador a la antiestética mole del edificio del Banco de España».

«La masa granítica del Banco de España, nos sale al paso, de pronto; y nos detiene, parece que se nos echa encima.

- Todas las desdichas se han dado cita en esta malhadada - exclama García Sanchiz- - Hasta la piedra es de una calidad que no adquie-

"CUADERNOS DE ESTUDIOS GALLEGOS", Tomo XLII, Fascículo 107, Santiago 1995. 
re esa pátina con que el tiempo, el aire, la lluvia barnizan a la piedra de la más alta y hermosa nobleza.

Efectivamente, el edificio, pesado, moderno, vulgar, rodeado de monumentos cargados de historia y de arte, verdinegros y solemnes, tiene algo de advenedizo, de insolente, de subversivo, y la más elemental estética - aparte de otras razones de índole sentimental—está pidiendo a gritos su urgente desplazamiento.

Sanchiz lo señala con un gesto fulminador, la boca fruncida en un rictus de infinito desprecio, y aifrma rotundamente:

- Puedo asegurar que el tumor será extirpado, se lo repito».

Así latía por estas fechas el estado de opinión de, al menos una parte, de aquellos ciudadanos que tenían tiempo y posibilidad de ocuparse de estos asuntos. Los puntos de vista, parece deducirse de estas manifestaciones, estaban variando notablemente respecto a los primeros momentos, o, al menos García Sanchiz, «con sus palabras de auténtico conversador de raza», haría lo posible porque así fuese.

Volviendo a la memoria del proyecto final, hay que destacar que existe en ella una, podríamos llamar, solución de consenso que resuelve, suponemos que de modo satisfactorio para todas las partes, aunque no hemos encontrado datos que lo confirmen ${ }^{22}$, la cuestión fundamental de la alineación. Y es que en el proyecto definitivo la línea de la fachada de la Plaza de Platerías no fue finalmente retranqueada. Desconocemos también si este logro, que beneficia a la sucursal, es fruto de las presiones del Banco, que tendría que haber multiplicado sus gastos de no haber sido así, o de los argumentos aportados en pro de la solución definitiva, tan inesperada como eficaz para sus intereses. Los arquitectos escribían lo siguiente:

«Esta memoria acompaña al proyecto de reforma de la primera crujía de fachada principal y en fachada de Gelmírez, así como la ampliación del interior necesaria para suplir la planta alta derribada.

Siguiendo las indicaciones recibidas del Banco de España y del Ministerio de Educación Nacional, por la Dirección general de Bellas Ar-

${ }^{22}$ A partir del momento en que el asunto se va de las manos del Ayuntamiento y al resolverse desde aquí la situación sin más conflictos desaparece todo resto de documentación, limitándose esta a lo que de definitivo representa esta memoria y a las peticiones finales, por parte del Banco, de permisos para ultimar el acabado de la obra, ya en 1949. 
tes, hemos proyectado la nueva fachada del edificio sucursal del Banco de España en Santiago, habiendo querido imprimir en sus trazas el mayor carácter local, acercándose en su composición a los viejos compostelanos y disimulando lo más posible su carácter bancario en la fachada...23

Conforme con este criterio, se ha destinado a pórtico toda la primera crujía del edificio en la planta baja, llevando los huecos de oficinas y puerta de ingreso, al fondo del pórtico, que se desarrolla con la mayor importancia posible a lo largo de la fachada a la Plaza de Platerías. Con esta disposición tratamos de dar la mayor ligereza a esta planta vista desde la plaza y al propio tiempo se consigue una solución perfecta viaria en continuidad con los soportales de la Rúa del Villar, proporcionando un paso cubierto hasta la misma catedral.».

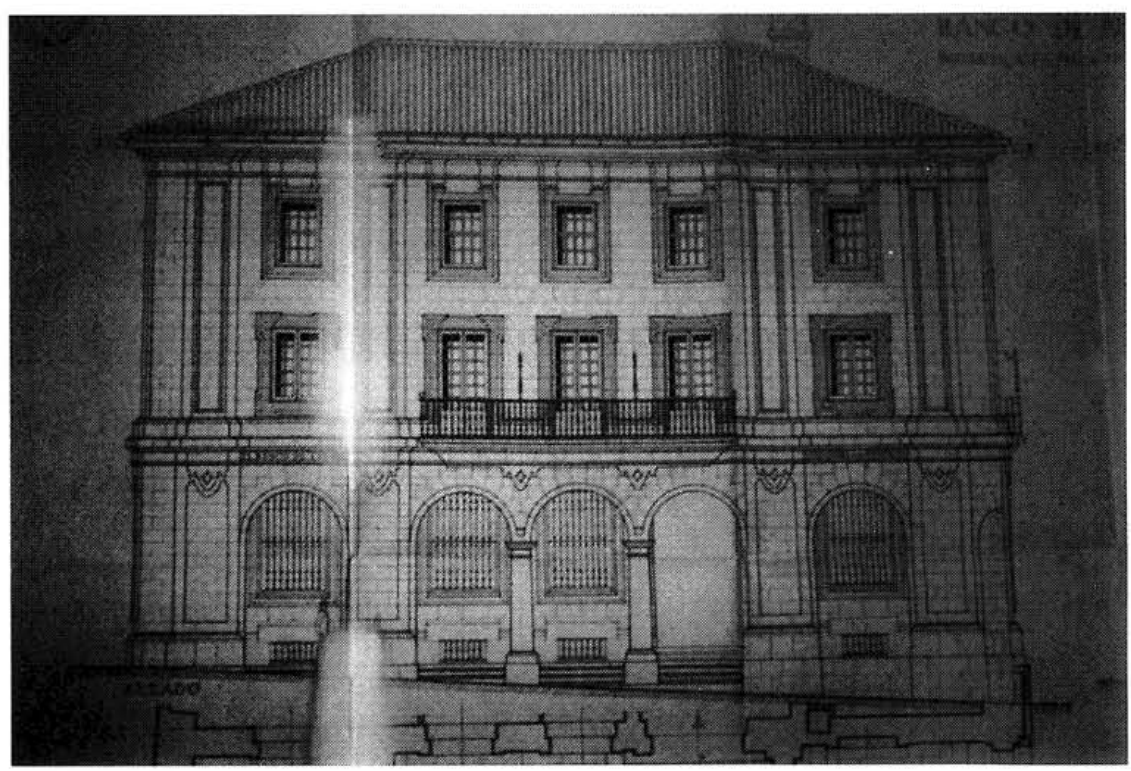

Fachada del edificio hacia la Plaza de Platerías en el proyecto definitivo.

${ }^{23}$ Gran esfuerzo este si tenemos en cuenta que, como es lógico en construcciones de este tipo, el Banco procuraba siempre dejar constancia de su presencia uniendo a la monumentalidad de sus edificios los necesarios símbolos y signos (en primer lugar lingüísticos) que los hicieran reconocibles y notorios.

"CUADERNOS DE ESTUDIOS GALLEGOS", Tomo XLII, Fascículo 107, Santiago 1995. 


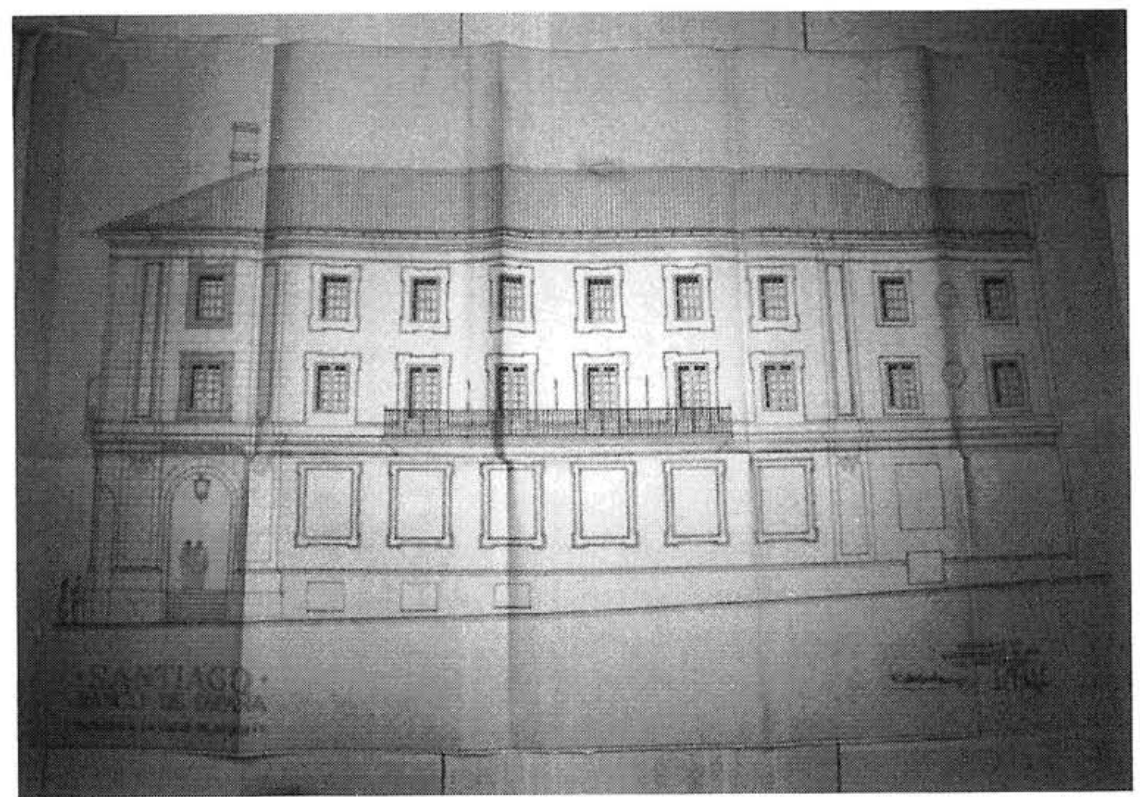

Fachada hacia la Calle Gelmírez y galería abierta hacia la Rúa del Villar.

La descripción detallada de cada uno de los elementos de esta fachada se adjetivaba ahora por medio de unos términos acordes con el lenguaje de la teoría arquitectónica oficial de la época. Nada más varonil ni más genuinamente español que sus «recios machones», «grandes arcos de refuerzo», «pilastras verticales», «fuertes repisas», «gran balcón», «recias rejas»... que hacían del edificio un sobrio y poderoso ejemplo de arquitectura de raza, pefectamente integrado en el marco compostelano - entendían ellos-, por el empleo de mínimos elementos decorativos que «acentuaban más el carácter local de las fachadas», por la imitación de «las viejas carpinterías locales» en ventanales y puertas, por la construcción de un «tejado suave en pendientes como todos los de Galicia», por el control de colores y barnices de rejas y maderas «en tonos armónicos con los de la Plaza» y por el empleo en los sillares de una labra que procurara «imitar la de los viejos edificios contiguos, prescindiendo de un refinado excesivo que en nuestro caso resultaría perjudicial para conseguir los efectos de conjunto y carácter armónicos con la maravillosa Plaza de Platerías».

El precio que el Banco debía pagar por su desobediencia, vista la solución final de planta y teniendo en cuenta que buena parte del material des-

"CUADERNOS DE ESTUdiOS GALLEGOS", Tomo XLII, Fascículo 107, Santiago 1995. 


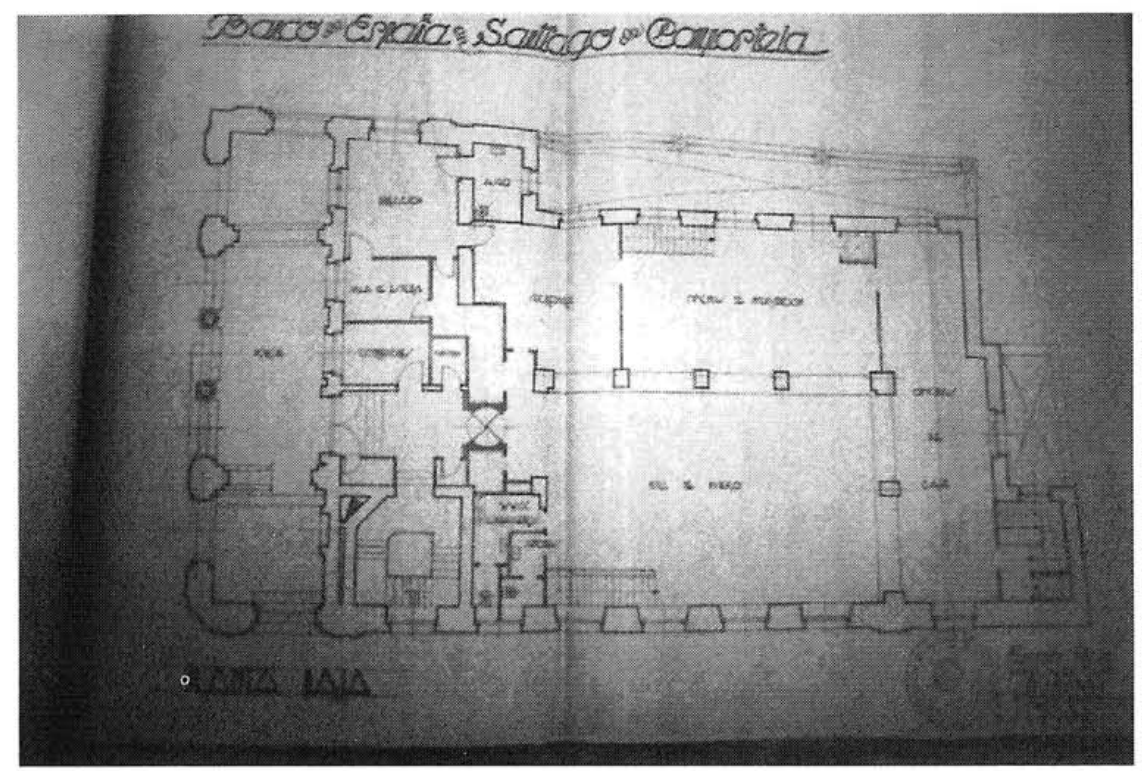

Plano de la planta baja del proyecto definitivo.

montado (rejas y sillares) podía ser reaprovechado, no parece por tanto muy elevado ${ }^{24}$.

$\mathrm{Y}$ eso fue todo. El edificio, sin que quede al menos constancia de haber sufrido nuevas interrupciones, se inauguró felizmente en 1949. Tras veinticinco años de espera y diez años más de parto, el Banco de España, engendraba su nueva sucursal en la ciudad de Santiago, firmada por Romualdo de Madariaga, pero en realidad, hija de muchos padres.

\footnotetext{
${ }^{24}$ Las reformas necesarias quedaban también señaladas en la memoria:

«Las obras de rectificación de la fachada principal sobre la Plaza de Platerías exigen desmontar por completo la existente después de realizar las obras previas de apeo de la estructura de hormigón armado; obras que deben comenzar por el apeo en el sótano y seguir en las demás plantas del edificio, afectando estos trabajos solamente a la primera crujía contigua a la Plaza de Platerías.». Debían además derribarse las fachadas que daban al patio y dilatarse la de Gelmírez para poder ampliar de este modo el interior y compensar el derribo de la planta alta. Así, «con este aumento de superficie construida en las dos plantas altas se pueden conseguir en cada una de ellas tres viviendas».
}

"CUADERNOS DE ESTUDIOS GALLEGOS", Tomo XLII, Fascículo 107, Santiago 1995. 


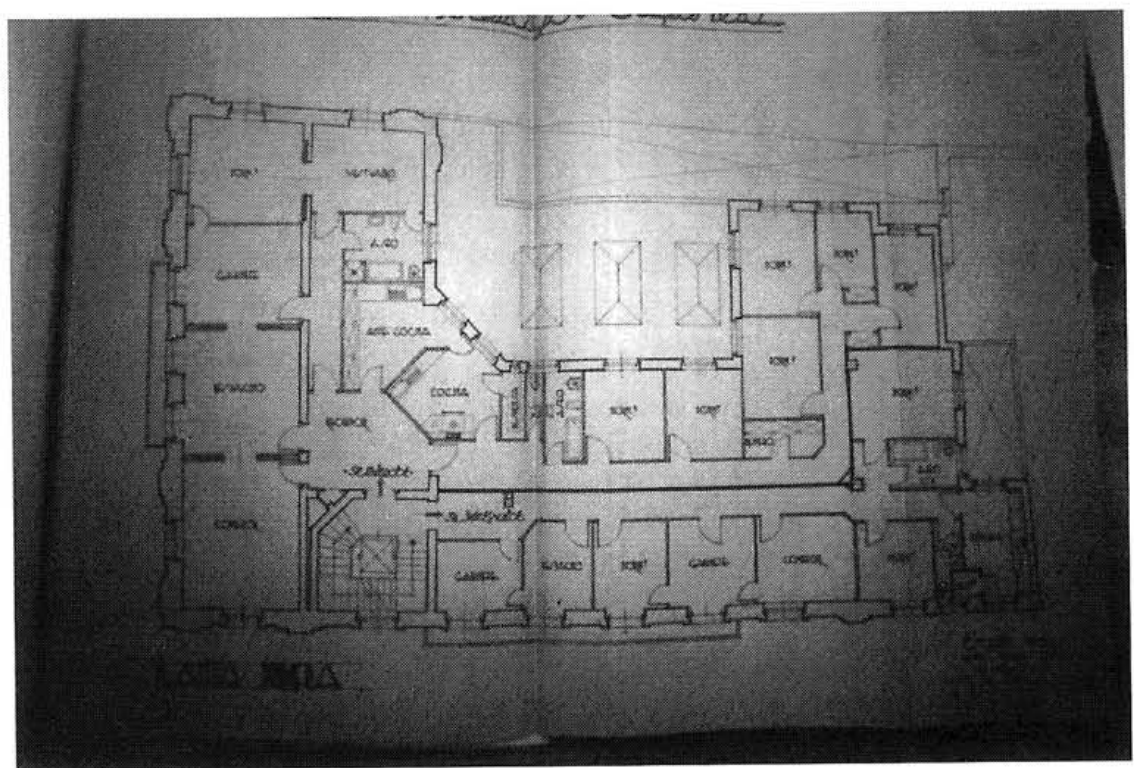

Plano de la primera planta del proyecto definitivo.

"CUADERNOS DE ESTUDIOS GALLEGOS", Tomo XLII, Fascículo 107, Santiago 1995. 